\title{
Physiological Differences Between Strong and Weak Frog Neuromuscular Junctions: A Study Involving Tetanic and Posttetanic Potentiation
}

\author{
Peter A. Pawson and Alan D. Grinnell \\ Jerry Lewis Neuromuscular Research Center, UCLA School of Medicine, Los Angeles, California 90024
}

This paper describes the extent of release and terminal variability among normal frog sartorius neuromuscular junctions and seeks physiological correlates for these differences. Terminal length varied over approximately a 10 -fold range, quantal content and release per unit terminal length ("release efficacy") over much larger ranges. For purposes of comparison of different junctions, release efficacy in a Ringer's containing $0.25 \mathrm{~mm} \mathrm{Ca}{ }^{2+}$ was determined in all cases. In a Ringer's containing $0.1 \mathrm{~mm} \mathrm{Ca}{ }^{2+}$, tetanic stimulation causes a buildup of evoked release and of miniature endplate potential (mEPP) frequency. The mEPP frequency at the end of the tetanus is proportional to the evoked release level. Following the tetanus, the mEPP frequency declines in a multiexponential fashion, with the 2 longest decay phases, representing augmentation and posttetanic potentiation (PTP), both having time constants that are positively linearly correlated with the synaptic release efficacy. Longer or higher-frequency tetanic stimulation resulted in a longer time course of decay of mEPP frequency. In a $\mathrm{Ca}^{2+}$-free/EGTA Ringer's, tetanic stimulation causes no evoked release, but does lead to an increased mEPP frequency, presumably due to a buildup of free $\mathrm{Ca}^{2+}$ displaced from internal stores by the $\mathrm{Na}$ influx. Following the tetanus, the mEPP frequency declines to resting level with a time constant that is essentially the same for all junctions, regardless of their release efficacy in $\mathrm{Ca}^{2+}$-containing Ringer's. These findings indicate that stronger terminals have a greater influx of $\mathrm{Ca}^{2+}$ per unit length during action potential invasion, but that in the absence of external $\mathrm{Ca}^{2+}$, tetanic stimulation results in comparable release of $\mathrm{Ca}^{2+}$ from internal stores in all terminals and comparable accumulation of $\mathrm{Ca}^{2+}$ in some large compartment, the subsequent emptying of which determines the time course of PTP.

Frog motor nerve terminals differ widely in their release properties. Within a given muscle, motor terminals have been shown to differ by as much as 20 -fold in release/unit terminal length ("release efficacy"; Grinnell and Herrera, 1981; Pawson and Grinnell, 1984; Trussell and Grinnell, 1985), and in extreme comparisons by as much as 100 -fold in release/unit terminal length (Pawson and Grinnell, 1989). These differences in part

\footnotetext{
Received Oct. 4, 1989; revised Dec. 11, 1989; accepted Dec. 15, 1989.

This research was supported by grants from the MDA and NIH. We wish to thank M. Delay, F. Knight, and B. Smith for technical assistance and Drs. Y. Kidokoro, S. Meriney, and S. Young for helpful comments on the manuscript.

Correspondence should be addressed to Peter A. Pawson at the above address.

Copyright (c) 1990 Society for Neuroscience $0270-6474 / 90 / 061769-10 \$ 02.00 / 0$
}

reflect intrinsic differences between motoneurons, some of which innervate more muscle fibers and form much larger and stronger synapses than other neurons (Luff and Proske, 1976; Ridge and Thompson, 1980; Grinnell and Trussell, 1983; Trussell and Grinnell, 1985). However, release efficacy is a plastic property, modifiable by simple experimental manipulations (Herrera and Grinnell, 1980, 1981, 1985; Pockett and Slack, 1982; Grinnell, 1985,1988 ; Herrera and Scott, 1985). This paper explores possible explanations for intrinsic differences in release efficacy, which may be involved in long-term plastic changes in release properties.

Previous work has shown that both strong and weak neuromuscular junctions, in Ringer's containing a lowered $\mathrm{Ca}^{2+}$ concentration, demonstrate a similar fourth-power relationship between the external $\mathrm{Ca}^{2+}$ concentration and the amount of transmitter released, and that both show approximately the same proportional dependence of miniature endplate potential (mEPP) frequency on $\mathrm{Ca}^{2+}$ when the terminal is depolarized with $\mathrm{K}^{+}$ (Grinnell and Herrera, 1980). An obvious explanation for differences in release efficacy would be corresponding differences in the extent of action potential invasion of the terminal arborization, or in action potential amplitude or duration. However, action potential properties are probably not of primary importance in determining synaptic efficacy, since there is a strong positive correlation between the quantal content of evoked endplate potentials (EPPs) and the frequency of spontaneous mEPPs in the absence of action potentials (Kuno et al., 1971; Grinnell and Herrera, 1980).

It is possible that stronger junctions have more release apparatus/unit terminal length. Recent studies have shown that there are ultrastructural differences among junctions of varying synaptic strengths (Herrera et al., 1985a, b; Banner and Herrera, 1986; Propst and Ko, 1987), but the ultrastructural differences so far described are small compared with the differences in release properties, and large nonuniformities in release efficacy along the length of terminal branches do not have clear-cut morphological correlates (Werle et al., 1984; D'Alonzo and Grinnell, 1985).

Alternatively, since mEPP frequency, like evoked release, depends on the intraterminal level of free $\mathrm{Ca}^{2+}$ (or related intermediary, which we will call $\mathrm{Ca}^{*}$; Katz, 1969; Rahamimoff et al., 1980; Moskowitz and Puszkin, 1985), the resting level of $\mathrm{Ca}^{*}$ inside the terminal may be higher in stronger junctions. In this paper, we examine the possibilities that differences in intraterminal $\mathrm{Ca}^{*}$ could arise either from a difference in the "set point" of intraterminal $\mathrm{Ca}^{*}$, determined by intracellular $\mathrm{Ca}^{2+}$ regulation/metabolism, or from a difference in $\mathrm{Ca}^{2+}$ influx both 
as a chronic leak and during action potentials. We have sought to differentiate between these options by examining the way in which different terminals handle intraterminal $\mathrm{Ca}^{2+}$ arising by entry from outside during tetanic stimulation as opposed to that released from internal stores during tetanic stimulation in the absence of external $\mathrm{Ca}^{2+}$. Our findings suggest that strong and weak terminals do not differ in their intraterminal $\mathrm{Ca}^{2+}$ regulatory/metabolic mechanisms, but rather in the levels of $\mathrm{Ca}^{2+}$ influx at rest and in the active state. Some of this work has been reported in preliminary form elsewhere (Pawson and Grinnell, 1984, 1986).

\section{Materials and Methods}

Experiments were conducted on sartorius nerve-muscle preparations of medium-sized (7-10 cm, nose to anus) Rana pipiens obtained from Wisconsin (Nasco). Frogs were used within a few weeks after their arrival. Data on the variability in terminal structure and release properties were derived from 298 junctions in 40 muscles. The tetanic and posttetanic data were obtained from a subset of this population comprising 42 endplates in 10 muscles. In 19 of the 42 junctions $(45 \%$; including examples from both $0 \mathrm{Ca}^{2+} /$ EGTA and $\mathrm{Ca}^{2+}$ Ringer's experiments-see below), 2 or more trials were sampled for a total of 76 tetanic trains.

The muscle was pinned to a layer of Sylgard in a Petri dish (volume: $5 \mathrm{ml}$ ), stretched to $1.1 \times$ the in situ length (with the leg in a flexed position), and continuously superfused $(2 \mathrm{ml} / \mathrm{min})$ with a freshly prepared Ringer's solution $\left(\mathrm{NaCl}, 116 \mathrm{~mm} ; \mathrm{KCl}, 2 \mathrm{~mm} ; \mathrm{CaCl}_{2}, 1.8 \mathrm{~mm}\right.$; $\mathrm{MgCl}_{2}, 1 \mathrm{~mm}$; $\mathrm{NaHCO}_{3}$, 1 mM; HEPES buffer, $2 \mathrm{~mm}$; $\mathrm{pH}$ 7.2). The muscle was maintained at $15^{\circ} \mathrm{C}$ with a Peltier cooling unit. The nerve stump was drawn into a glass electrode and stimulated with $0.1-\mathrm{msec}$ pulses delivered by a WPI Anapulse stimulator. Twitch threshold was ascertained and the preparation was checked visually to determine that the muscle twitched vigorously in response to the supramaximal stimulus intensity used (3-5 times twitch threshold, usually $10 \mathrm{~V}$ ).

The preparation was then superfused with a low $\mathrm{Ca}^{2+}$ Ringer's $(0.25$ $\mathrm{mm} \mathrm{Ca}{ }^{2+}$ instead of $1.8 \mathrm{~mm}$ ) and allowed to equilibrate for $1 \mathrm{hr}$. In the interim the muscle was scanned under a compound microscope with a $20 \times$ objective $(200 \times$ final magnification), looking for regions that appeared to be rich in surface endplates. We preferred to select junctions located near the center of the longitudinal length of the muscle, along the main nerve trunks, or along a small branch coming off the main nerve trunk. For recording purposes, the endplate region was visualized either with the $20 \times$ objective or with a Zeiss $40 \times$ water immersion objective ( $400 \times$ final magnification) equipped with Hoffman-like contrast modulation optics. EPPs and mEPPs were recorded with standard electrophysiological techniques using $15-25 \Omega \mathrm{M}$ glass microelectrodes filled with $3 \mathrm{M} \mathrm{KCl}$.

At least 128 stimuli were averaged (Hewlett-Packard 5486 signal averager) at $0.5 \mathrm{~Hz}$ in this low $\mathrm{Ca}^{2+}$ Ringer's $(0.25 \mathrm{~mm})$, and approximately $100 \mathrm{mEPPs}$ were recorded on film. These data were used to determine quantal content both by the method of failures [n(number of stimuli/number of failures)] and by the direct method (EPP/mEPP). If the 2 values differed greatly, the junction was not included in further analysis. The quantal content values derived from the direct method were used in calculations related to determining synaptic release efficacy. Four to 30 junctions were studied in each muscle in this manner. A map was drawn of the recording regions, using easily recognizable landmarks (nerve branch pattern, fiber diameters, blood vessels, pigment cells, electrode site, etc.) to ensure proper correlation of the physiological results with terminal morphology. The resting potentials (RP) of the muscle fibers were noted upon entering and leaving the fiber, usually approximately a $15-\mathrm{min}$ interval. Fibers that had a good RP $(>-90$ $\mathrm{mV}$ ) and that showed little or no change in RP during the period of the first penetration were good candidates for successful repenetration. Cells that had lost some RP $(>3-5 \mathrm{mV})$ were unlikely to tolerate well a subsequent penetration, especially in a $\mathrm{Ca}^{2+}$-free/EGTA Ringer's. Following the assessment of synaptic strength, identified junctions were restudied in their original order, as described below, in one of two Ringer's solutions: (1) a low $\mathrm{Ca}^{2+}$ Ringer's $\left(0.1 \mathrm{~mm} \mathrm{Ca}{ }^{2+}, 5.0 \mathrm{~mm} \mathrm{Mg}^{2+}\right)$ whose $\mathrm{Ca}^{2+} / \mathrm{Mg}^{2+}$ concentration reduced evoked release sufficiently to prevent contraction and synaptic depression during tetanic trains, or
(2) a $\mathrm{Ca}^{2+}$-free/EGTA Ringer's ( $1 \mathrm{~mm}$ EGTA, $2.0 \mathrm{mM} \mathrm{Mg}^{2+}$ ) in which there would be no $\mathrm{Ca}^{2+}$ influx during the tetanus (Erulkar and Rahamimoff, 1978; Lev-Tov and Rahamimoff, 1980). In all cases the muscle was allowed to equilibrate for $1 \mathrm{hr}$ in the new solution. In most experiments, 2 junctions, one strong and one weak, were studied concurrently. ("Strong" and "weak" here refer to transmitter release efficacy and are relative measures. In practice, however, "strong" was taken to be greater than 1.0 quantum $/ 100 \mu \mathrm{m}$ release probability, while "weak" was defined as less than 0.2 quantum $/ 100 \mu \mathrm{m}$.) In the low-Ca ${ }^{2+}$ Ringer's, a standard tetanus of $50 \mathrm{~Hz}$ for $40 \mathrm{sec}$ was generally used (see Results for exceptions). In $\mathrm{Ca}^{2+}$-free/EGTA Ringer's, tetani of $100 \mathrm{~Hz}$ for 40 or $80 \mathrm{sec}$ were measured. Each tetanus was scparated by at lcast a half hour interval. In some preparations, a "reference" junction was monitored hourly during the experiment to ensure that this stimulus regime did not produce any long-term changes in the release characteristics (see Magleby and Zengel, 1976b). No such effects were seen. We did observe that approximately $10-12 \mathrm{hr}$ after the dissection there was a general rundown in $\mathrm{mEPP}$ frequencies, irrespective of the experimental protocol.

In order to remove all $\mathrm{Ca}^{2+}$ from the extracellular solution, the muscle was washed repeatedly in the $\mathrm{Ca}^{2+}$-free/EGTA Ringer's and then allowed to equilibrate for $1 \mathrm{hr}$ as $\mathrm{Ca}^{2+}$-free/EGTA Ringer's was superfused rapidly across the surface of the muscle. This technique is similar to those used previously (Miledi and Thies, 1971; Erulkar and Rahamimoff, 1978; Lev-Tov and Rahamimoff, 1980). We never observed stimuluslocked release under these conditions, indicating that the $\mathrm{Ca}^{\text {?+ }}$ influx was effectively eliminated.

mEPPs were recorded on a Racal Store 4DS FM tape recorder. In subsequent analysis, individual mEPPs were detected with a windowcircuit in which the trigger level could be carefully adjusted for each sample run to ensure that each mEPP was recognized and that there were no false triggers. Trigger intervals (i.e., mEPP intervals) were collected and stored with a microcomputer (Lomas Data Products) and subsequently analyzed with a moving-bin technique (see Lev-Tov and Rahamimoff, 1980).

Following the electrophysiological experiments, identified junctions were stained with a combined nitroblue tetrazolium-Karnovsky nerve terminal and cholinesterase stain (Letinsky and DeCino, 1980). The progress of the staining procedures was monitored visually to ensure optimal staining of the physiologically characterized junctions. Junctions were drawn at $400 \times$ with a camera lucida. Fibers were first drawn in situ in the muscle and then dissected out and redrawn. The morphology seen in dissected fibers was considered definitive in cases where there was a conflict, e.g., when a branch running along the side of the fiber had been hidden in the in situ view. Synaptic release efficacy is expressed as the number of quanta released per $100 \mu \mathrm{m}$ of nerve terminal length.

To determine the time constant of potentiation, mEPP frequency was plotted semilogarithmically against time according to the methods of Magleby and Zengel (1976a; see also Zengel and Magleby, 1982); i.e., $F(\mathrm{t})=\mathrm{f}(\mathrm{t}) / \mathrm{f}_{0}-1$, where $F(\mathrm{t})$ is the fractional change in mEPP frequency at time $t$ compared to the resting mEPP frequency, $f_{0}$. In the figures, $F(t)$ is labeled "normalized mEPP frequency." The time constant of potentiation was derived from a least-squares fit to the data points that encompassed the last linear decay phase (on the semilog plot) as the mEPPs returned to their pretetanus values. In practice, this involved making numerous moving bin histograms of the data, estimating by eye a minimum and maximum set of cutoff points where the last linear decay portion occurred, and selecting the actual time interval based on selecting for the best correlation coefficient of the regression analysis. A $25-\mathrm{sec}$ bin size with a 1-sec delta bin was a standard choice that usually gave clear multiexponential decay rates. If necessary, other bin and delta bin sizes were used (e.g., 10-sec bin, 1-sec delta bin; 50-sec bin with a 1-sec delta bin size) to produce readily recognizable posttetanic decay constants. In some instances, data were further smoothed by using the time series module of SYSTAT (Wilkinson, 1988) to remove some of the underlying oscillations apparent in the baseline mEPP frequency. The slowest component of the mEPP frequency before it settled back to pretetanic levels was assumed to represent the time constant of potentiation (the time required for the mEPP frequency to fall to $1 / e$ of its initial value). The next slowest component of decay of $\mathrm{mEPP}$ frequency was assumed to represent augmentation. Its time constant was derived in a similar fashion after subtracting the contribution from posttetanic potentiation (P'P; Lev-Tov and Rahamimoff, 1980; Zengel and Magleby, 1982). 


\begin{tabular}{|c|c|c|c|}
\hline $\begin{array}{l}\text { Train } \\
\text { No. }\end{array}$ & Junction 1 & Junction 2 & Junction 3 \\
\hline 1 & 0.15 & 0.33 & 0.64 \\
\hline 2 & 0.08 & 0.33 & 0.47 \\
\hline 3 & 0.11 & 0.40 & 0.68 \\
\hline 4 & 0.07 & 0.35 & 0.54 \\
\hline 5 & 0.13 & 0.37 & 0.60 \\
\hline 6 & 0.12 & 0.49 & 0.58 \\
\hline 7 & 0.13 & - & 0.44 \\
\hline 8 & 0.14 & - & - \\
\hline
\end{tabular}

\section{Results}

\section{Variability in synaptic properties}

Within the population of junctions examined in this study, there was wide variability in terminal sizes $(130-1175 \mu \mathrm{m}$, mean 620 $\mu \mathrm{m})$ and quantal contents in $0.25 \mathrm{mM} \mathrm{Ca}{ }^{2+}$ Ringer's (0.01-21, mean 3.2). There was less variability within individual muscles, but the ranges were still large. In general, there is a positive relationship between terminal size and quantal content, but terminals of the same size can vary by manyfold in quantal content, and vice versa (Kuno et al., 1971; Grinnell and Herrera, 1981; Pawson and Grinnell, 1989). Since we feel that the mean amount of transmitter release per unit terminal length is likely to be a more sensitive measure of differences in terminal $\mathrm{Ca}^{2+}$ metabolism than is overall quantal content, we have used calculated mean transmitter release $/ 100 \mu \mathrm{m}$ terminal length as our criterion of synaptic release efficacy. In the present study, with $0.25 \mathrm{~mm} \mathrm{Ca}^{2+}$ Ringer's, this value ranged from 0.01 to 3.54 , with a mean of 0.53 quantum $/ 100 \mu \mathrm{m}$. However, all of the differences between terminals that we describe here are essentially as well correlated with quantal content as with release/ unit length.

\section{Tetanic and posttetanic phenomena in a $\mathrm{Ca}^{2+}$ Ringer's}

When a terminal is stimulated tetanically in the presence of external $\mathrm{Ca}^{2+}$, it greatly increases its output, both in the form of release evoked by the invading action potentials and as an accelerated spontaneous release of quanta. Following the tetanus, the mEPP frequency falls back toward the resting level with a complex time course composed of rapidly decrementing facilitation, somewhat slower augmentation, and the relatively long-lasting PTP (Lev-Tov and Rahamimoff, 1980; Zengel and Magleby, 1981). All are presumed to represent processes whereby $\mathrm{Ca}^{2+}$ is removed from the vicinity of the release apparatus by diffusion, sequestration, or extrusion. We have examined the time course of the augmentation and PTP phases of return to resting $\mathrm{mEPP}$ frequency, comparing terminals of high and low release efficacy.

To reduce the total amount of stimulation of the nerve in any given preparation, the tetanic and posttetanic data for a given junction were sometimes (in $55 \%$ of the terminals) collected from a single stimulus train. Therefore, it was important to ascertain that the results obtained from single trains were reproducible and representative of the inherent release properties

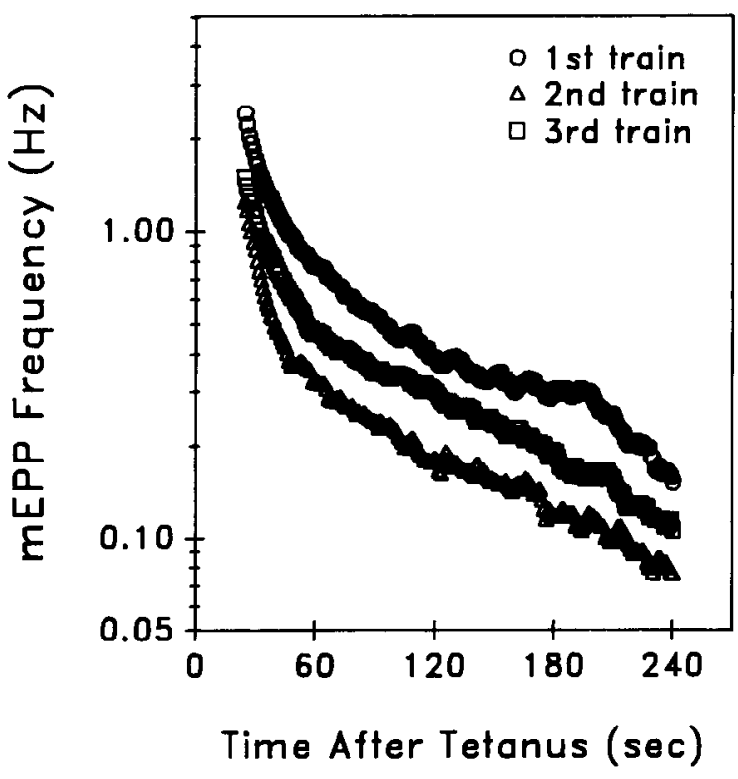

Figure 1. Reproducibility of the tetanus-related changes in mEPP frequency at a given junction. The semilogarithmic plot of normalized mEPP frequency versus time illustrates that different trains yield similar time courses of mEPP frequency decay; trains were separated by at least $1 / 2 \mathrm{hr}$. The $50-\mathrm{Hz}, 40-\mathrm{sec}$ tetanus was administered in a $0.1 \mathrm{mM} \mathrm{Ca}^{2+}$ Ringer's solution. The mEPP frequency is normalized to the average $\mathrm{mEPP}$ frequency during the 5 -min period prior to the tetanus. Moving bin histogram: 50-sec bin, 1-sec delta bin.

of a given terminal. This was determined to be the case by 2 related procedures: (1) In several cases, junctions were studied repeatedly at $1 / 2$-hr intervals (the standard intertrain interval for all our experiments). As noted in Materials and Methods, 19 of the $42(45 \%)$ junctions were studied with 2 or more (up to a maximum of 5) identical tetani separated by this $1 / 2$-hr interval. As was previously demonstrated (Lev-Tov and Rahamimoff, 1980), we found that at this interval there was no observable change in the tetanic (data not shown) and PTP phenomena (see Fig. 1), at a given junction. (2) During each experiment, we monitored a "reference" junction. Periodic recording from this junction demonstrated that this experimental approach produced reproducible, unchanging responses throughout the course of our experiments. We saw no evidence for long-term changes in transmitter relcase like those described when a substantially greater number of stimuli are delivered to the nerve (Magleby and Zengel, 1976b). Moreover, since we studied "strong" and "weak" junctions simultaneously, any uncontrolled influences would be expected to be distributed evenly throughout the results. As the examples in Table 1 show, the mEPP frequency consistently returns to the original baseline levels following successive tetani.

In a Ringer's containing $0.1 \mathrm{mM} \mathrm{Ca}^{2+}$, a standard tetanus (50 $\mathrm{Hz}, 40 \mathrm{sec}$ ) elicited a greater absolute increase in tetanic potentiation and longer-lasting PTP in junctions of high release/unit length than were seen in weaker junctions (Fig. 2). There was a consistent positive correlation between evoked release efficacy and the mEPP frequency seen at the end of the tetanus [peak tetanic mEPP frequency (Fig. 3)]. Figures 4 and 5 illustrate the differences between weak and strong junctions in the time course of decay in mEPP frequency after the tetanus. Figure 4 shows characteristic recovery curves obtained in single experiments, 


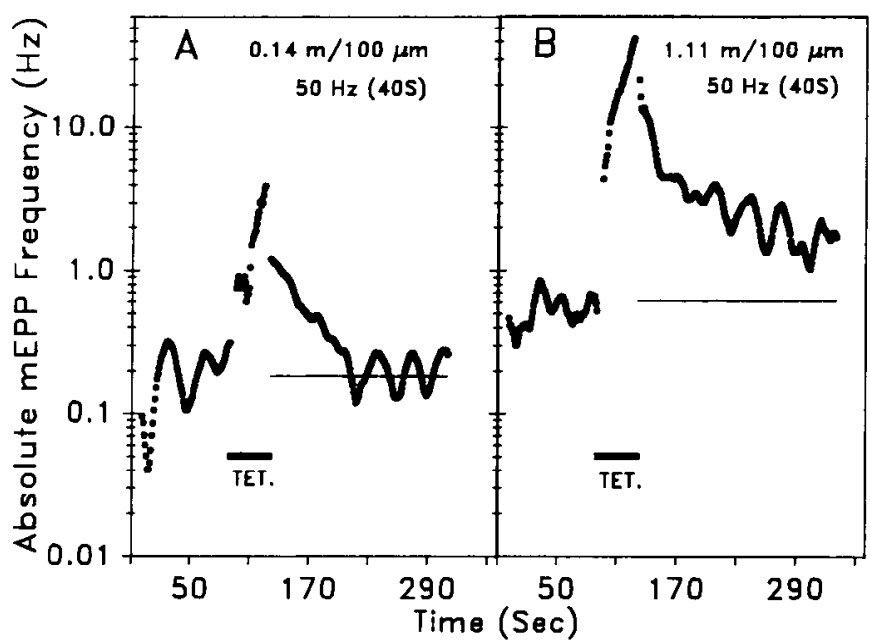

Figure 2. Summary of the basic procedures used in these experiments. mEPPs were recorded for at least $5 \mathrm{~min}$, a 40-sec tetanus was delivered, and the posttctanic response was recorded for $15 \mathrm{~min}$ afterward. Qualitative example of the differences between a weak $(A)$ and a strong $(B)$ junction's response to the standard tetanus $(50 \mathrm{~Hz}, 40 \mathrm{sec})$ in a $0.1 \mathrm{~mm}$ $\mathrm{Ca}^{2} \cdot$ Ringer's. The numerical quantities in $A$ and $B$ give the average quantal release $/ 100 \mu \mathrm{m}$ of identified nerve terminal length. The absolute mEPP frequency is plotted logarithmically versus time. The bar marked $T E T$. denotes the time of the tetanic train (delivered between 90 and $130 \mathrm{sec}$ on the time scale). Note the greater tetanic potentiation and the longer PTP in the strong junction. Moving bin histogram: $10-\mathrm{sec}$ bin, 1 -sec delta bin. The straight line in the posttetanic region of $A$ and $B$ indicates the average value of the pretetanic $\mathrm{mEPP}$ frequency in the 5 -min period immediately preceding the tetanus. Note that only the mEPP frequency in the $90 \mathrm{sec}$ immediately preceding the tetanus is plotted here. Both plots show the same time interval for both junctions, using identical moving bin and smoothing techniques on the data.

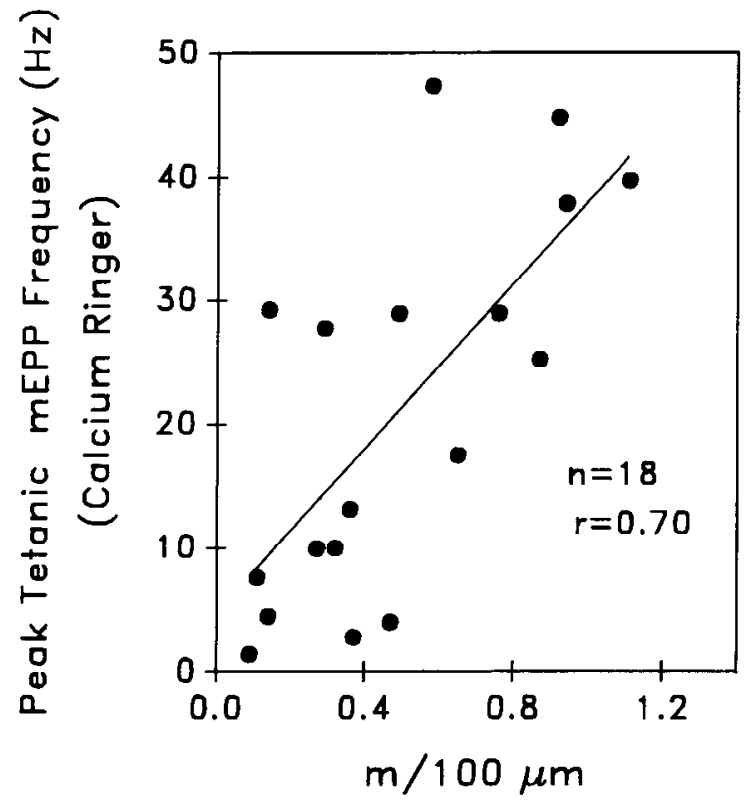

Figure 3. Plot of peak tetanic mEPP frequency (i.e., the average number of $\mathrm{mEPPs} / \mathrm{sec}$ at the end of the $50-\mathrm{Hz}, 40-\mathrm{sec}$ tetanus) versus release/ unit length. The number was derived by dividing the number of mEPPs in the last 10 -sec bin by 10 . There is a consistent positive correlation between these 2 parameters $[r=0.70 ; p<0.01 ; n=18$ (number of endplates)]. The line drawn through the data points represents the leastsquares regression line.

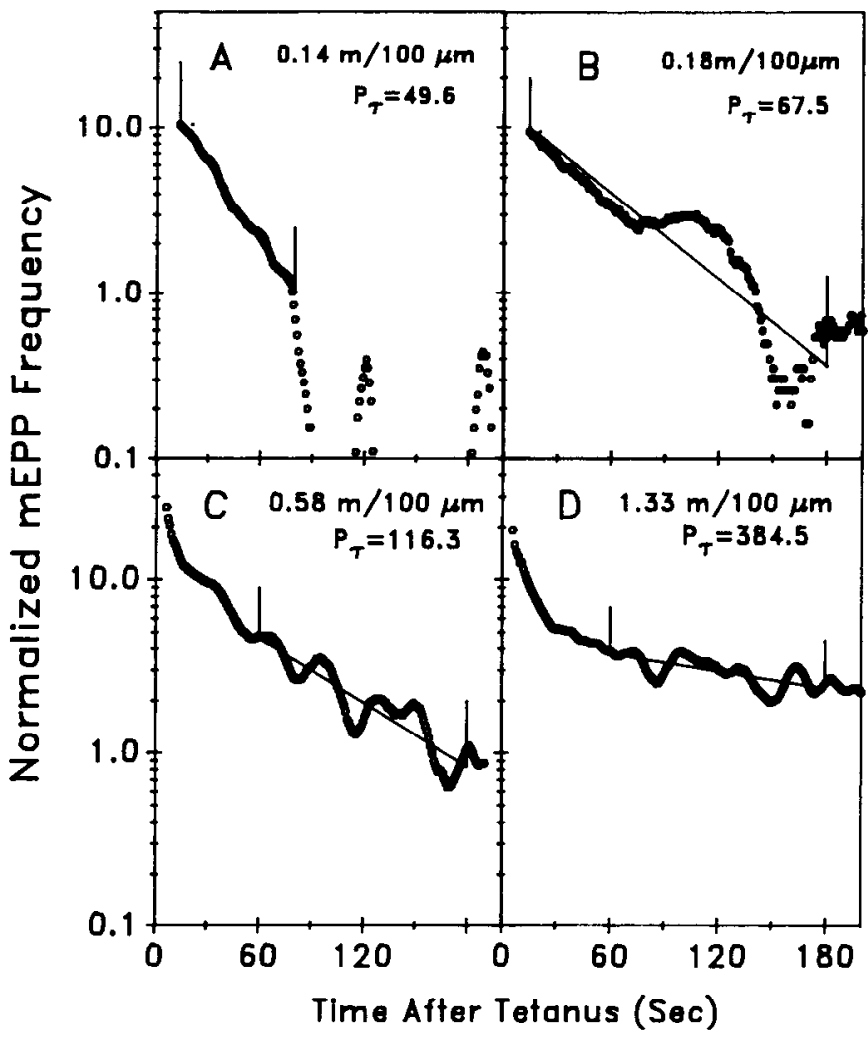

Figure 4. Differences between weak and strong junctions $(A-D$ are arranged in order of increasing synaptic strength) in the time course of decay in mEPP frequency back to resting levels after a $50-\mathrm{Hz}, 40-\mathrm{sec}$ tetanus in a $0.1 \mathrm{~mm} \mathrm{Ca} \mathrm{a}^{2+}$ Ringer's. Each of the 4 panels is a semilogarithmic plot of normalized mEPP frequency for the first $200 \mathrm{sec}$ following the tetanus. $A$ is the same junction illustrated in Figure $2 A$. The bracketed straight line through the data points represents the least-squares regression used to calculate the time constant of PTP. The weaker junctions' mEPPs decay back to baseline faster than do those of the strong junction. Note also that the decay in mEPP frequency back to baseline in the weaker junctions $(A, B)$ is described largely by a single exponent. In the stronger junctions $(C, D)$, augmentation becomes apparent and is most pronounced in the strongest junctions $(D)$. Moving bin histogram: 25sec bin, 1-sec delta bin.

with the time constant of PTP indicated, while the values for augmentation were derived after subtracting the contribution from PTP. Both the time constants of augmentation $\left(t_{\mathrm{a}} ; \mathrm{Fig} .5 \mathrm{~A}\right)$ and PTP $\left(t_{\mathrm{p}}\right.$; Fig. $\left.5 B\right)$ are positively linearly correlated with synaptic release efficacy, although the $t_{\mathrm{p}}$ shows a better correlation.

Furthermore, increasing the tetanus duration at any given terminal (in 10-sec steps from 10 to $50 \mathrm{sec}$ ) produced progressively greater absolute increases in both tetanic potentiation and $t_{\mathrm{p}}$. These increases were larger in strong junctions than in weaker junctions studied concurrently (see Table 2 for PTP data). Similar results were obtained when the stimulus train duration was held constant (i.e., $40 \mathrm{sec}$ ) and the stimulus frequency was varied (i.e., 25, 50, $100 \mathrm{~Hz}$; see Table 3). Finally, Figure 6 compares the posttetanic decay of 2 junctions in response to a $100 \mathrm{~Hz}(40$ sec) tetanus in a calcium Ringer's. A $100 \mathrm{~Hz}(40 \mathrm{sec})$ tetanus was not usually delivered in a calcium Ringer's because at this frequency some strong junctions in the muscle would become suprathreshold before the end of the tetanus, causing muscle contractions that would dislodge the electrodes. In these fortuitous examples, one can see that the stronger junction showed 


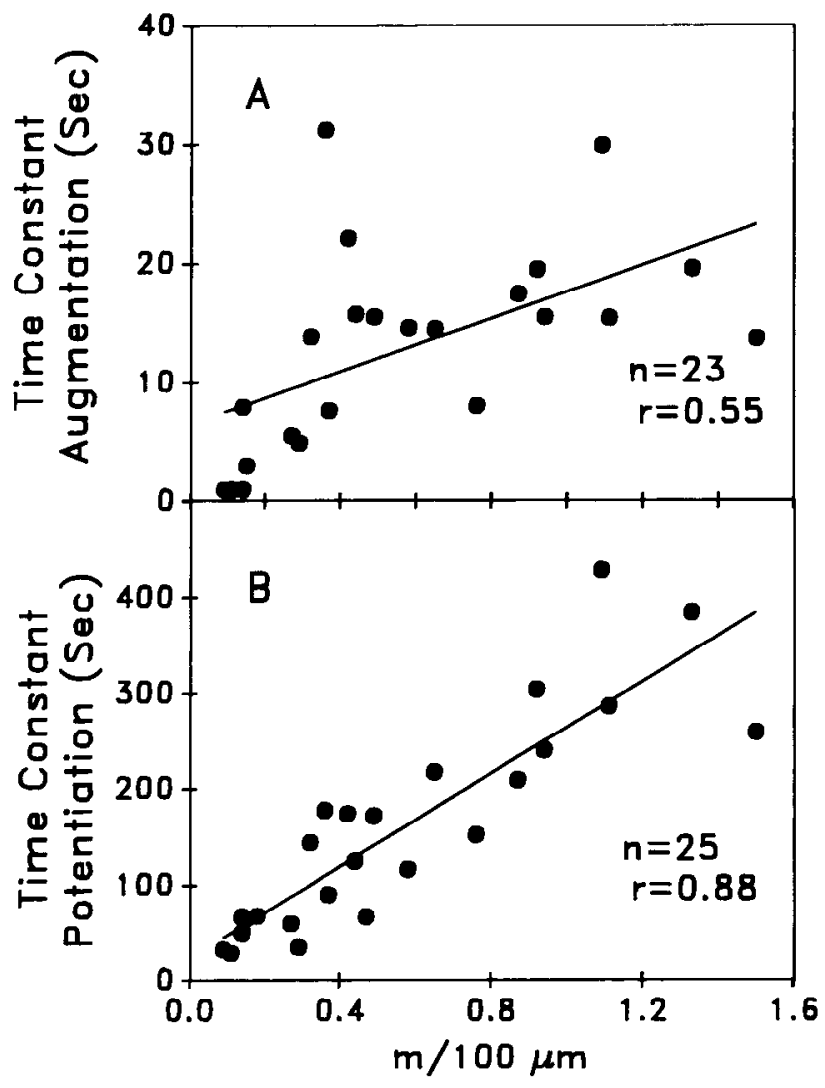

Figure 5. Summary of the results for $50 \mathrm{~Hz}(40 \mathrm{sec})$ tetani in a 0.1 mм Ca ${ }^{2+}$ Ringer's. Both the $(A)$ time constant of augmentation $(r=$ $0.55 ; p<0.01 ; n=23)$ and $(B)$ time constant of PTP $(r=0.88 ; p<$ $0.01 ; n=25$ ) are positively correlated with synaptic release efficacy as measured by $\mathrm{m} / 100 \mu \mathrm{m}$ identified nerve terminal length. In the cases where more than 1 trial was performed at a junction, the mean value for that junction is presented.

a substantially longer PTP time constant. Since experimental manipulations that presumably increase the intraterminal $\mathrm{Ca}^{*}$ (e.g., increasing tetanic duration or frequency) lead to prolongation of both PTP and augmentation (Lev-Tov and Rahamimoff, 1980; present data), the 2 time constants of these 2 processes appear to reflect related aspects of the kinetics of $\mathrm{Ca}^{2+}$ metabolism within the terminal. At any given terminal, there is a good positive correlation between the $t_{\mathrm{p}}$ and $t_{\mathrm{a}}$ values for a $50 \mathrm{~Hz}(40 \mathrm{sec})$ tetanus $(r=0.73 ; p<0.001 ; n=20)$, suggesting

Table 2. Comparison within the same muscle of the effect of varying stimulus duration (from 20 to $50 \mathrm{sec}$ ) on $t_{\mathrm{p}}$ of different strength junctions $^{u}$

\begin{tabular}{|c|c|c|c|c|c|}
\hline No. & $\mathrm{m} / 100 \mu \mathrm{m}$ & $t_{\mathrm{p}}(20 \mathrm{sec})$ & $t_{\mathrm{p}}(30 \mathrm{sec})$ & $t_{\mathrm{p}}(40 \mathrm{sec})$ & $t_{\mathrm{p}}(50 \mathrm{sec})$ \\
\hline 8 & 0.09 & $b$ & - & 32.4 & - \\
\hline 5 & 0.11 & 16.34 & 21.24 & 28.73 & 73.88 \\
\hline 1 & 0.47 & 7.37 & 20.44 & 66.37 & 72.76 \\
\hline 7 & 0.76 & 29.07 & 99.69 & 154.84 & 228.78 \\
\hline 6 & 0.94 & 53.29 & 137.63 & 227.59 & 295.43 \\
\hline
\end{tabular}

${ }^{a}$ A $50-\mathrm{Hz}$ train was used in all cases. Junctions are arranged in order of increasing synaptic strength.

b. Too few mEPPs to get a reliable PTP estimate, $t_{\mathrm{p}}$ less than $10-20 \mathrm{sec}$.

- , Not tested at this duration.

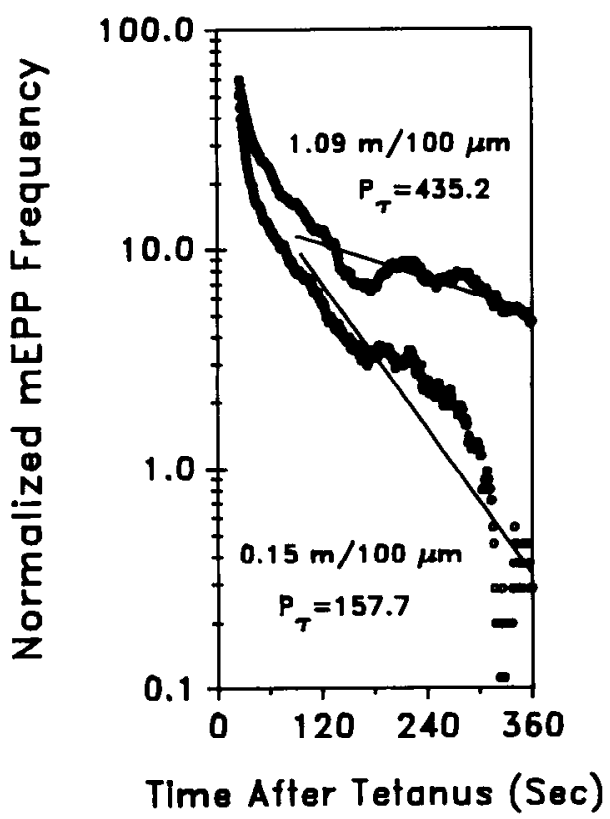

Figure 6. Posttetanic response of 2 different junctions to a $100 \mathrm{~Hz}(40$ sec) train in a calcium Ringer's. As with the other variations of tetanus frequency and duration, the stronger junction $\left(\mathrm{m} / 100 \mu \mathrm{m}=1.09 ; t_{\mathrm{p}}=\right.$ $435.2 \mathrm{sec}$; filled circles, upper trace) has a longer PTP time constant than that seen in the weaker junction $\left(\mathrm{m} / 100 \mu \mathrm{m}=0.15 ; t_{\mathrm{o}}=157.7 \mathrm{sec}\right.$; open circles, lower trace). We chose identical cutoff points $(90-360 \mathrm{sec})$ for the determination of PTP, as indicated by the regression lines. Moving bin histogram: 50-sec bin, 1-sec delta bin.

an interdependence between the underlying processes responsible.

In the present experiments, the mean values we have found for the time constants of augmentation and PTP (12.9 sec and $157.8 \mathrm{sec}$, respectively) are comparable in magnitude to those obtained by Lev-Tov and Rahamimoff (1980) in a comparable sample of junctions of unknown synaptic strength $(2.3 \mathrm{sec}$ and $80.5 \mathrm{sec}$, respectively). Our larger values may be attributable both to our use of a $0.1 \mathrm{~mm} \mathrm{Ca}^{2+}$ Ringer's versus Lev-Tov and Rahamimoff's (1980) use of a $0.05 \mathrm{~mm} \mathrm{Ca}^{2+}$ Ringer's, and to the lower temperatures used in the present experiments. Magleby and Zengel (1976a) have shown that the time constant of PTP is prolonged at lower temperatures.

Table 3. Comparison within the same muscle of the effect of varying stimulus frequency on $t_{\mathrm{p}}$ of different strength junctions ${ }^{u}$

Junc-

tion

No. $\quad \mathrm{m} / 100 \mu \mathrm{m} \quad t_{\mathrm{p}}(25 \mathrm{~Hz}) \quad t_{\mathrm{p}}(50 \mathrm{~Hz}) \quad t_{\mathrm{p}}(100 \mathrm{~Hz})$

$\begin{array}{llllc}4 & 0.15 & 47.7^{h} & 64.5 & 74.3^{h} \\ 6 & 0.18 & c & 67.5^{h} & 131.7^{h} \\ 7 & 0.42 & 84.2^{h} & 174.1 & - \\ 5 & 0.44 & 81.3^{h} & 124.7^{h} & - \\ 1 & 1.09 & - & 427.9 & 343.0\end{array}$

a All tetanic trains were of $40 \mathrm{sec}$ duration. Junctions are arranged in order of increasing synaptic strength.

"Mean value of 2 or more determinations.

c Too few mEPPs to get a reliable PTP estimate, $t_{\mathrm{p}}$ less than $10-20 \mathrm{sec}$.

- , Not tested at this frequency. 


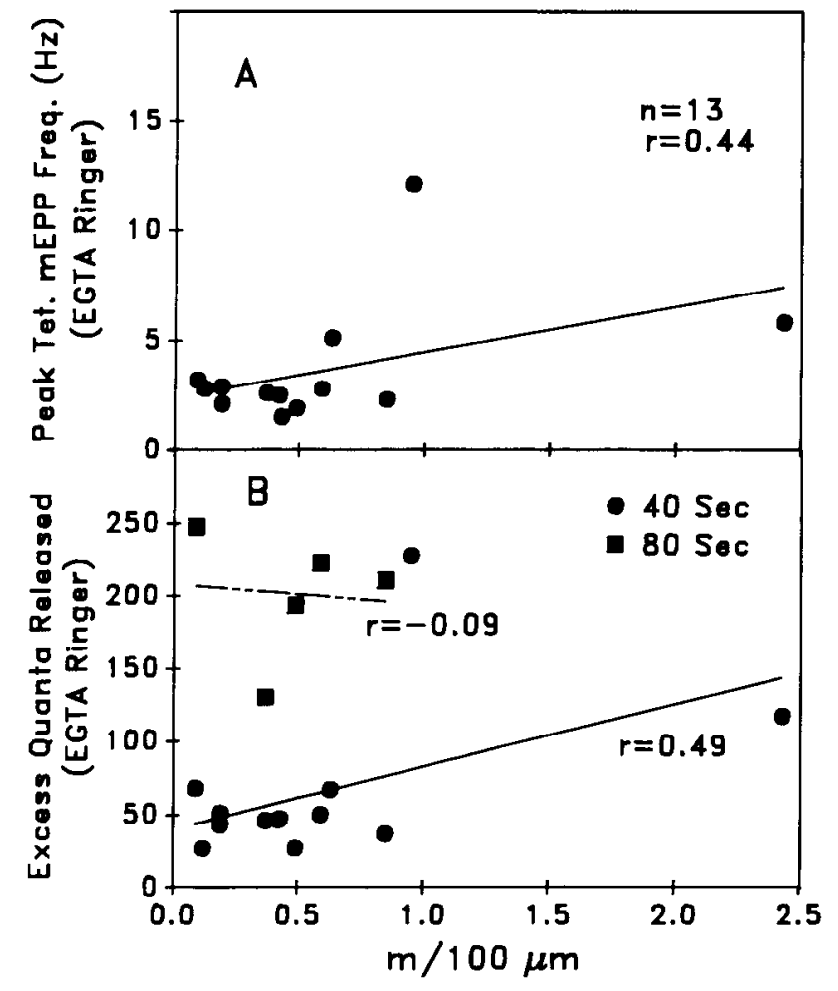

Figure 7. In a $0 \mathrm{Ca}^{2+} /$ EGTA Ringer's there is a much less striking relationship between synaptic release efficacy and $(A)$ peak tetanic $\mathrm{mEPP}$ frequency following a $100 \mathrm{~Hz}(40 \mathrm{sec})$ tetanus $(r=0.44 ; p>0.10 ; n=$ 13 ), or between synaptic efficacy and $(B)$ the total number of quanta released during the tetanus in excess of the resting level. Note the contrast with Figure 3 . The latter point holds true even when a longer (100 $\mathrm{Hz}, 80 \mathrm{sec}$ ) train is used.

\section{Tetanic and posttetanic phenomena in a $\mathrm{Ca}^{2+}$-free/EGTA} Ringer's

The findings described above suggest (1) that stronger junctions have a reduced capacity for sequestering or removing $\mathrm{Ca}^{2+}$ and/ or (2) that they have a proportionately greater $\mathrm{Ca}^{2+}$ influx during the tetanus, thereby leading to a saturation of some $\mathrm{Ca}^{2+}$ sequestration/extrusion system(s). In order to determine the importance of $\mathrm{Ca}^{2+}$ influx to our findings, we performed similar experiments in a $\mathrm{Ca}^{2+}$-free/EGTA Ringer's where there is no $\mathrm{Ca}^{2}$ influx during the telanus. Under these conditions, there is no evoked release, but tetanic stimulation nevertheless increases the mEPP frequency. This is generally thought to be caused by a $\mathrm{Na}^{+}$-induced translocation of $\mathrm{Ca}^{2+}$ from intraterminal stores (Birks and Cohen, 1968; Baker and Crawford, 1975; Lowe et al., 1976; Rahamimoffet al., 1978b; Lev-Tov and Rahamimoff, 1980; Meiri et al., 1981; Atwood and Wojtowicz, 1986).

In the $\mathrm{Ca}^{2+}$-free/EGTA Ringer's we found that a $50-\mathrm{Hz}, 40-$ sec tetanus did not produce an adequate increase in MEPP frequency to give the signal-to-noise ratio that was necessary to determine unambiguously the time constant of PTP. For this reason we selected a $100-\mathrm{Hz}, 40-\mathrm{sec}$ tetanus, which in most cases produced an increase in $\mathrm{mEPP}$ frequency adequate to reveal differences in intraterminal $\mathrm{Ca}^{2+}$ metabolism, as evidenced by the time constant of PTP. If augmentation occurred in $\mathrm{Ca}^{2+}$-free/EGTA Ringer's, it was at such low levels that it was normally undetectable. Thus no $t_{\mathrm{a}}$ was determined under these conditions.

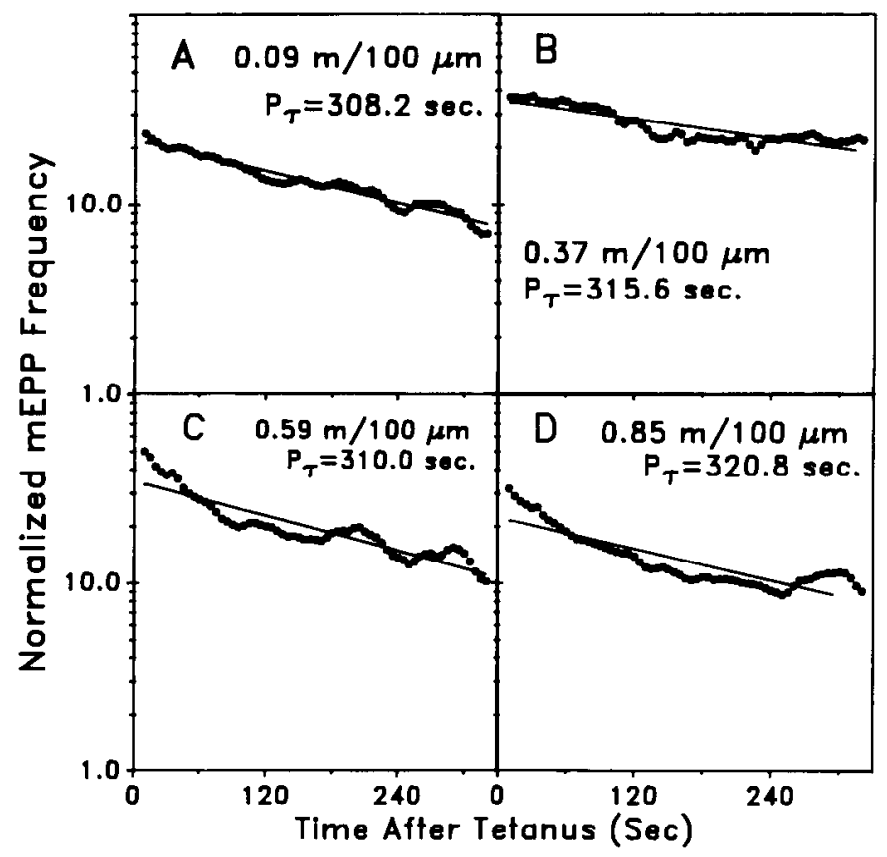

Figure 8. Strong similarities between weak and strong junctions $(A-D$ are arranged in order of increasing synaptic strength) in the time course of decay in mEPP frequency back to resting levels after a $100-\mathrm{Hz}, 80-$ sec tetanus in a $0 \mathrm{Ca}^{2+} /$ EGTA Ringer's, under conditions when mEPP frequency (and presumably intracellular $\mathrm{Ca}^{2+}$ concentration) have undergone significant increases. Semilogarithmic plot of normalized mEPP frequency versus time following a tetanus. The straight line through the data points represents the least-squares regression used to calculate the time constant of PTP. Moving bin histogram: $10 \mathrm{sec}$ bin, $5 \mathrm{sec}$ delta bin. All the examples are taken from the same muscle; synaptic strengths and calculated time constants of PTP are as indicated.

In $0 \mathrm{Ca}^{2+} /$ EGTA Ringer's there was no significant correlation between synaptic release efficacy (as measured initially in a 0.25 $\mathrm{mm} \mathrm{Ca}^{2+}$ Ringer's) and peak tetanic mEPP frequency (Fig. $7 \mathrm{~A}$ ) or the total number of quanta released during the tetanus in excess of rest levels (Fig. $7 B$ ). This is in sharp contrast to the results in $0.1 \mathrm{~mm} \mathrm{Ca}^{2+}$ Ringer's (see Fig. 3). Moreover, junction pairs that differed by as much as 25 -fold in release efficacy showed a similar $t_{\mathrm{p}}$ in $\mathrm{Ca}^{2+}$-free/EGTA Ringer's (Figs. 8, 9). As Figure 9 shows, all junctions studied showed a similar $t_{\mathrm{p}}$ in the $\mathrm{Ca}^{2+}$-free/EGTA Ringer's; i.e., there was no correlation between synaptic release efficacy and $t_{\mathrm{p}}(r=0.02 ; p>0.50 ; n=14)$ (compare with Fig. $5 B$ ). A similar noncorrelation between release and $t_{\mathrm{p}}(r=0.02 ; p>0.50 ; n=5$; range of synaptic strengths: $0.09-0.85 \mathrm{~m} / 100 \mu \mathrm{m})$ was seen following a $100 \mathrm{~Hz}(80 \mathrm{sec})$ tetanus, which produces an even greater increase in mEPP frequency (Fig. 9). It is important to note that the tetani used in the $\mathrm{Ca}^{2+}$-free/EGTA Ringer's (100 Hz, 40 and $80 \mathrm{sec}$ ) produce relative increases in $\mathrm{mEPP}$ frequencies comparable to those seen at some junctions after tetanic stimulation in a $\mathrm{Ca}^{2+}$ Ringer's (Figs. 6 and 3 ). Assuming that $\mathrm{mEPP}$ frequency is proportional to the level of intraterminal $\mathrm{Ca}^{*}$, then intraterminal $\mathrm{Ca}^{*}$ must be able to undergo a substantial increase in concentration due to release from internal stores and/or reduced extrusion.

\section{Discussion}

Our interpretation of these findings is based on the assumption that quantal transmitter release is proportional to the concentration of active $\mathrm{Ca}^{*}$ at release sites in the terminal, and that 


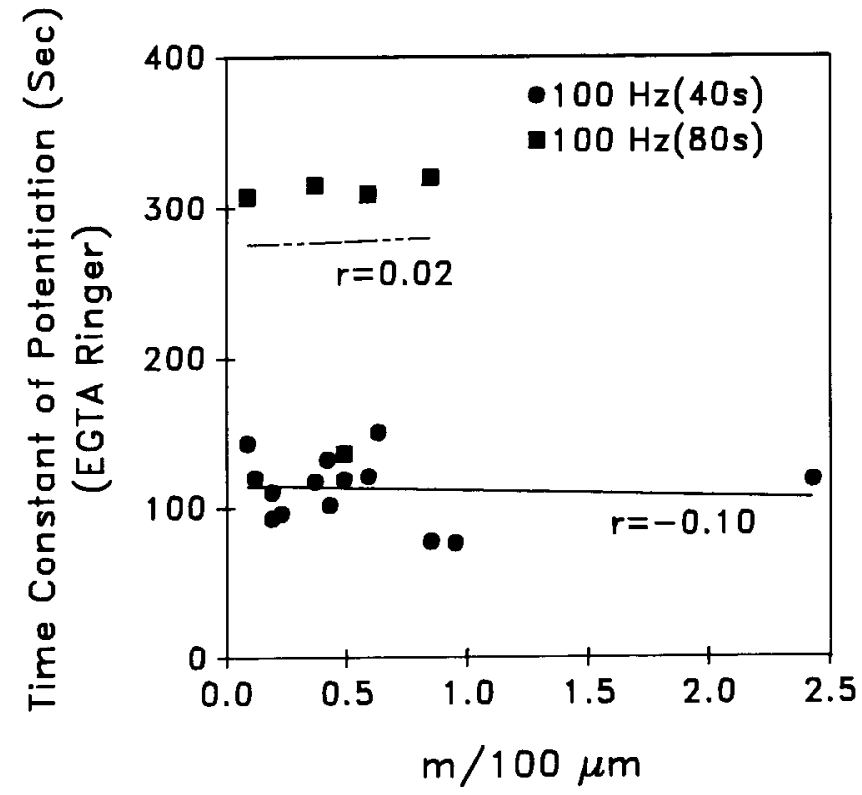

Figure 9. Summary of the PTP results in the $0 \mathrm{Ca}^{2+}$ /EGTA Ringer's. All junctions, irrespective of synaptic strength, had similar time constants for the decay of PTP (solid regression line: $r=-0.10 ; p>0.50$; $n=14$ ). This was also true for the $100-\mathrm{Hz}, 80-\mathrm{sec}$ tetani (dash-dotted regression line: $r=0.02 ; p>0.50 ; n=5$ ). As in Figure 5 , in the cases where more than 1 trial was performed at a junction, the mean value for that junction is presented.

the level of $\mathrm{Ca}^{*}$ is dependent on the amount of impulse-related $\mathrm{Ca}^{2+}$ influx, the resting $\mathrm{Ca}^{2+}$ influx (or leak), and the binding constants and capacity of internal $\mathrm{Ca}^{2+}$ sequestering and extruding systems. We also assume that mEPP frequency following a tetanus shows essentially the same dependence on $\mathrm{Ca}^{*}$ near release sites as does the stimulus-coupled release (Lev-Tov and Rahamimoff, 1980; Rahamimoff et al., 1980). This may not be the case for all release, especially from weaker junctions (see Grimnell and Pawson, 1989), but is probably a good approximation for most. There is a good correlation between the total number of quanta released during a tetanus in low $\mathrm{Ca}^{2+}$ Ringer's and the peak mEPP frequency observed at the end of the tetanus. The relationship between external $\mathrm{Ca}^{2+}$ concentration and evoked release is very steep (approximately fourth power at low $\mathrm{Ca}^{2+}$ concentration; Dodge and Rahamimoff, 1967; Reichardt and Kelly, 1983; Smith et al., 1985), presumably reflecting a fourthpower cooperativity between internal $\mathrm{Ca}^{2+}$ and release (Augustine et al., 1987). Accordingly, we take peak tetanic mEPP frequency to be a sensitive indicator of $\mathrm{Ca}^{2+}$ concentration (or some related factor, $\mathrm{Ca}^{*}$ ) near release sites.

In the $\mathrm{Ca}^{2+}$-free/EGTA experiments, it is thought to be the entry of $\mathrm{Na}^{+}$during the action potential that leads to a translocation of $\mathrm{Ca}^{2+}$ from intraterminal stores. There is substantial literature demonstrating $\mathrm{Na}^{+}$-mediated $\mathrm{Ca}^{2+}$ release, as well as $\mathrm{Na}^{+}$involvement in PTP (Baker and Crawford, 1975; Crawford, 1975; Lowe et al., 1976; Rahamimoff et al., 1978a; Lev-Tov and Rahamimoff, 1980; Rahamimoff et al., 1980; Atwood and Wojtowicz, 1986). Lev-Tov and Rahamimoff (1980) have shown that blocking $\mathrm{Na}^{+}$influx with TTX in the presence of EGTA and $2 \mathrm{mM} \mathrm{MgCl}_{2}$ (the same concentration used in the present experiments) completely blocks the development of PTP in response to direct depolarization, indicating that $\mathrm{Na}^{+}$accumulation is critical for the development of PTP in a $0 \mathrm{Ca}^{2+} /$ EGTA

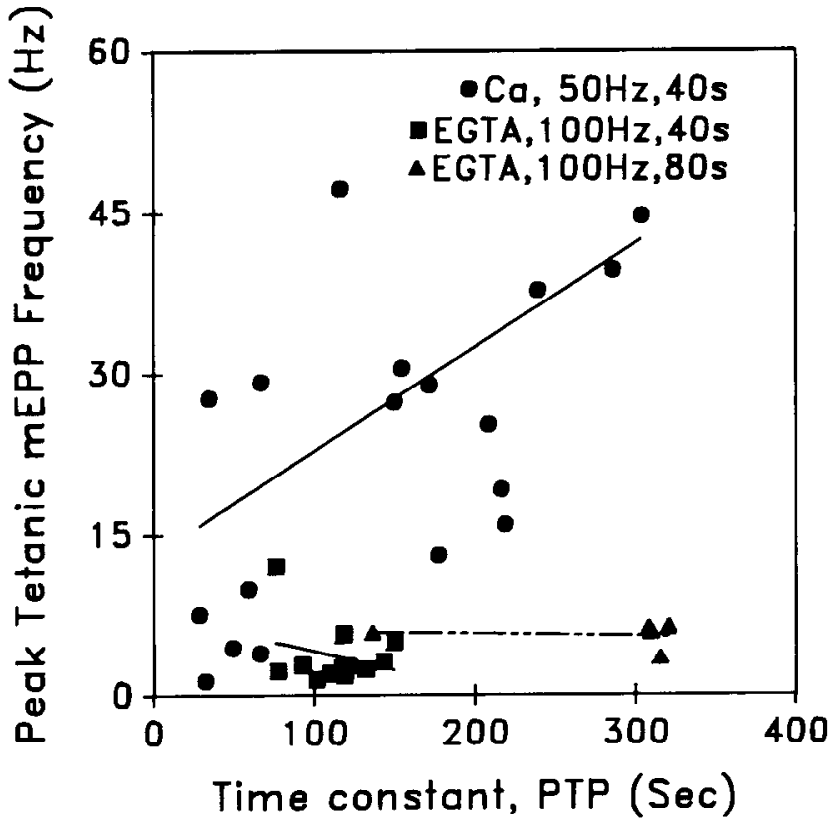

Figure 10. In a $0.1 \mathrm{~mm} \mathrm{Ca}{ }^{2+}$ Ringer's, there is a positive relationship between peak tetanic mEPP frequency and the time constant of PTP (solid long regression line: $r=0.42 ; p<0.05 ; n=20$ ). This relationship largely disappears in a $0 \mathrm{Ca}^{2+} / \mathrm{EGTA}$ Ringer's, whether a $100-\mathrm{Hz}, 40-$ sec train (solid short regression line: $r=-0.29 ; p>0.10 ; n=14$ ) or a $100-\mathrm{Hz}, 80-\mathrm{sec}$ train was used (dash-dotted regression line: $r=-0.15$; $p>0.50 ; n=5$ ).

Ringer's whereas $\mathrm{Mg}^{2+}$ alone (at the $2 \mathrm{~mm}$ concentration) is unable to generate potentiation or PTP. Similarly, the results of Misler and Hurlbut (1983) strongly suggest that $\mathrm{Na}^{+}$accumulation within the terminal is important in producing PTP of mEPP frequency. They found that increasing $\mathrm{Mg}^{2+}$ substantially

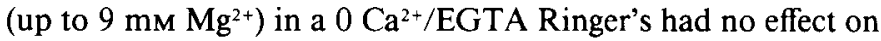
prolonging PTP. Furthermore, experimental actions that directly increase the $\mathrm{Na}^{+}$influx (e.g., increased action potential frequency or duration, by adding monensin or veratridine) or decrease $\mathrm{Na}^{+}$removal (ouabain) proportionately increase mEPP frequency during or following a tetanus (Rahamimoff et al., 1978a; Meiri et al., 1981; Melinek et al., 1982). Moreover, by analogy with other systems (Sulakhe and St. Louis, 1980), an intracellular buildup of $\mathrm{Na}^{+}$would reduce the driving force of the $\mathrm{Na}^{+}-\mathrm{Ca}^{2+}$ exchanger, causing a corresponding drop in $\mathrm{Ca}^{2+}$ extrusion. In squid axon, this exchanger appears to function mainly at high intracellular $\mathrm{Ca}^{2+}$ levels (DiPolo and Beauge, 1983). However, in frog terminals, a reduced $\mathrm{Na}^{+}$gradient causes an increase in both spontaneous and evoked release, implying that the $\mathrm{Na}^{+}-\mathrm{Ca}^{2+}$ exchanger is important to maintaining even the normal resting level of free $\mathrm{Ca}^{2+}$ (Meiri et al., 1986). Misler and Hurlbut (1983) believe that the PTP seen when $\mathrm{Ca}^{2+}$ is added to the Ringer's following a tetanus in a $0 \mathrm{Ca}^{2+} / \mathrm{EGTA}$ Ringer's is attributable to an increased posttetanic $\mathrm{Ca}^{2+}$ influx associated with an increased activity in the $\mathrm{Na}^{+}-\mathrm{Ca}^{2+}$ exchanger mechanism. Whatever the mechanism(s), it seems likely that the enhanced release is due to $\mathrm{Ca}^{2+}$, and that even in the $\mathrm{Ca}^{2+}$ containing Ringer's some component of the tetanic potentiation and PTP is derived from $\mathrm{Ca}^{2+}$ translocation and reduced $\mathrm{Ca}^{2+}$ extrusion. Indeed, Lev-Tov and Rahamimoff(1980) suggest that because both $t_{\mathrm{p}}$ and $\mathrm{Ca}^{2+}$ translocation increase with the duration and frequency of stimulation or with ouabain, the $\mathrm{Na}^{+}$-triggered buildup of $\mathrm{Ca}^{2+}$ may constitute a major component of poten- 
tiation. Our data indicate, however, that for most terminals the $t_{\mathrm{p}}$ following any given tetanus is much longer in a low $\mathrm{Ca}^{2+}$ containing Ringer's than in a $0 \mathrm{Ca}^{2+} /$ EGTA Ringer's. Only in the terminals of lowest release/unit length might the $\mathrm{Na}^{+}$entry during a tetanus be the dominant factor in determining $t_{\mathrm{p}}$. Whether arising from direct entry or release from internal stores, however, it seems likely that $\mathrm{Ca}^{*}$ acts in the same way to evoke release during PTP.

The principal finding in the present work is that the synaptic phenomena studied (amount of tetanic potentiation, $t_{\mathrm{a}}$ and $t_{\mathrm{p}}$ ) are positively correlated with release efficacy in a $\mathrm{Ca}^{2+}$-containing Ringer's, but uncorrelated with it when there is no $\mathrm{Ca}^{2+}$ influx. In a low $\mathrm{Ca}^{2+}$ Ringer's, the peak mEPP frequency, occurring at the termination of a standard $50-\mathrm{Hz}, 40-\mathrm{sec}$ tetanus, ranged from about $1.5 / \mathrm{sec}$ to nearly $50 / \mathrm{sec}$ for terminals of differing efficacy and, as Figure 10 shows, the time course of PTP was corrclated with peak mEPP frequency $(r=0.38, p<$ 0.05 ). At any given junction a longer or higher-frequency tetanus produces a higher mEPP frequency, resulting in prolonged PTP (Lev-Tov and Rahamimoff, 1980). Similarly, an increased duration of stimulation also increases the PTP time course of EPP amplitudes (Rosenthal, 1969). This suggests that, during a tetanus, $\mathrm{Ca}^{2+}$ accumulates in one or more compartments, and that the time course of PTP is a measure of the time it takes to unload the $\mathrm{Ca}^{2+}$ from these compartments, a process that continues to supply $\mathrm{Ca}^{2+}$ to release sites before it is finally extruded from the terminal. The greater the $\mathrm{Ca}^{2+}$ loading of these compartments, the longer it takes to get rid of it.

The tetani used in the $0 \mathrm{Ca}^{2+} /$ EGTA Ringer's [100 $\mathrm{Hz}, 40$ and $80 \mathrm{sec} ; 200 \mathrm{~Hz}, 40$ and $80 \mathrm{sec}$ (data not shown)] produce mEPP frequencies comparable to those observed in the $\mathrm{Ca}^{2+}$ Ringer's at junctions of weak and intermediate strength (those having release per unit length values of less than 0.50 quanta released $/ 100 \mu \mathrm{m}$ of terminal, in a $0.25 \mathrm{mM} \mathrm{Ca}^{2+}$ solution). Assuming that mEPP frequency is reflective of intraterminal $\mathrm{Ca}^{2+}$ levels, we conclude that intraterminal $\mathrm{Ca}^{2+}$ has risen sufficiently to challenge the terminal's $\mathrm{Ca}^{2+}$-sequestration system. Both in low- $\mathrm{Ca}^{2+}$ and $0-\mathrm{Ca}^{2+}$ Ringer's, the ratio of peak tetanic mEPP frequency to rest mEPP frequency was a maximum of about 20-50 (see Figs. 4 and 8) for the tetani used.

The noteworthy point is that the peak tetanic mEPP frequency and the time course of PTP seen in $0 \mathrm{Ca}^{2+}$ are both essentially independent of a junction's release efficacy in a low-Ca $\mathrm{C}^{2+} \mathrm{Ring}-$ er's. We conclude from this that $\mathrm{Ca}^{2+}$ released from internal stores is sequestered and/or extruded with essentially the same time course in all terminals, independent of their intrinsic strength in a $\mathrm{Ca}^{2+}$-containing Ringer's. Interestingly, in our experiments, a $100-\mathrm{Hz}, 80-\mathrm{sec}$ tetanus in $0 \mathrm{Ca}^{2+} /$ EGTA Ringer's, which produced a mean peak tetanic mEPP frequency of only $5.6 / \mathrm{sec}$, prolonged the time course of PTP to values equivalent to those observed in the strongest junctions in $\mathrm{Ca}^{2+}$-containing Ringer's, where the peak tetanic mEPP frequency reached 40-50/sec (Fig. 10). Presumably $\mathrm{Ca}^{2+}$ that enters from outside the terminal, being initially concentrated near the sites of transmitter release, is much more effective in eliciting release than is the $\mathrm{Ca}^{2+}$ released from internal stores. However, the total amount of $\mathrm{Ca}^{2+}$ released from internal compartments during a tetanus may be very large and $\mathrm{Ca}^{2+}$ may continue to reach sites of release at significant concentration for a long time before the overall level in the terminal is reduced to resting values. On the other hand, the increased $\mathrm{Na}^{+}$inside the terminal likely reduces the rate of
$\mathrm{Ca}^{2+}$ extrusion effected by the $\mathrm{Na}^{+}-\mathrm{Ca}^{2+}$ exchanger. Therefore, the course of PTP would be prolonged in the $0 \mathrm{Ca}^{2+} /$ EGTA Ringer's due to the larger intracellular $\mathrm{Na}^{+}$levels (due to the higher-frequency trains used). In that case, it may not be necessary to suggest that internally released $\mathrm{Ca}^{2+}$ has less effect on mEPP release than $\mathrm{Ca}^{2+}$ that enters from outside. If $\mathrm{Na}^{+}$affects the time course of PTP, then there may be a kinetic component of release due to $\mathrm{Na}^{+}$which accumulates and is extruded independent of $\mathrm{Ca}^{2+}$, but which affects the time course of PTP through its effect on $\mathrm{Ca}^{2+}$ (see, for example, Magleby and Zengel, 1976c). Although the $\mathrm{Na}^{+}-\mathrm{Ca}^{2+}$ exchanger may play an important role in ultimately determining the time course of PTP, the exchanger appears not to function qualitatively differently among junctions of differing synaptic strength (Grinnell and Pawson, 1989).

These findings indicate that terminals differ in release efficacy because of differences in level of $\mathrm{Ca}^{2+}$ influx during action potentials. Inside the terminal, the $\mathrm{Ca}^{*}$ at release sites induces release with similar efficacy and is removed with approximately equal capacity by all terminals, with a time course proportional to the amount of $\mathrm{Ca}^{2+}$ present. The usual close correspondence between quantal content values calculated by the direct and failure methods and the good correlation between mEPP frequency and quantal content both argue that differences in action potential amplitude or duration or degree of invasion of terminal arborization are not responsible for the differences in $\mathrm{Ca}^{2+}$ influx. Moreover, other experiments suggest that differences in $\mathrm{Ca}^{2+}$ influx during excitation are paralleled by differences in resting influx, as reflected in the dependence of mEPP frequency on external $\mathrm{Ca}^{2+}$ (Grinnell and Pawson, 1989). Furthermore, assuming that augmentation represents a long-lasting posttetanic conductance to $\mathrm{Ca}^{2+}$ (Lev-Tov and Rahamimoff, 1980), the clearly greater amount of augmentation in the stronger terminals indicates a greater posttetanic $\mathrm{Ca}^{2+}$ influx. In fact, this greater posttetanic influx may be an important contributor to the greater $t_{\mathrm{p}}$ of these terminals.

The most obvious interpretation of our data is that stronger junctions contain $\mathrm{Ca}^{2+}$ channels at a greater density and/or a different functional state. There may be different types of $\mathrm{Ca}^{2+}$ channels in the terminal, or a single typc that can cxist in different states which can be modulated to increase or decrease their voltage sensitivity or probability of opening at resting membrane potential. If nerve terminal $\mathrm{Ca}^{2+}$ channels can exist in inactivated form, as appears to be the case in some other systems, such as cardiac muscle (Bean et al., 1984) and snail neurons (Doroshenko et al., 1984; Armstrong and Eckert, 1987), where $\mathrm{Ca}^{21}$ channels must be phosphorylated to be activatable, then there might be large differences in release efficacy not well correlated with morphology.

There are other possible explanations for the differences in release efficacy that we observed. For example, differences in local $\mathrm{Ca}^{2+}$ buffering in the synaptic cleft might make the effective $\mathrm{Ca}^{2+}$ concentration higher in some junctions than in others (Ginsburg and Rahamimoff, 1983). However, this has been shown not to be the explanation for differences in mEPP frequency in these terminals (see Grinnell and Pawson, 1989) and hence is probably not responsible for differences in evoked release. Other possible explanations are considered in the context of $\mathrm{Ca}^{2+}$-dependent mEPP frequency (Grinnell and Pawson, 1989).

A considerable variability in time constant values for augmentation and PTP has previously been noted at the frog neu- 
romuscular junction (Magleby and Zengel, 1976a; Lev-Tov and Rahamimoff, 1980). We believe our results explain some of that variability.

We conclude that the differences in synaptic efficacy we observe are likely to reflect differences in numbers of $\mathrm{Ca}^{2+}$ channels/unit length, or in their functional state, and speculate that manipulations that produce long-term changes in release efficacy do so by altering the number or state of $\mathrm{Ca}^{2+}$ channels.

\section{References}

Armstrong D, Eckert R (1987) Voltage activated calcium channels that must be phosphorylated to respond to membrane depolarization. Proc Natl Acad Sci USA 84:2818-2822.

Atwood HL, Wojtowicz JM (1986) Short-term and long-term plasticity and physiological differentiation of crustacean motor synapses. Int Rev Neurobiol 28:275-362.

Augustine GJ, Charlton MP, Smith SJ (1987) Calcium action in synaptic transmitter release. Annu Rev Neurosci 10:633-693.

Baker PF, Crawford AC (1975) A note on the mechanism by which inhibitors of the sodium pump accelerate spontaneous release of transmitter from motor nerve terminals. J Physiol 247:209-226.

Banner LR, Herrera AA (1986) Differences in synaptic efficacy at neuromuscular junctions in frog twitch muscles. J Physiol 379:205215.

Bean BP, Nowicky MC, Tsien RW (1984) Beta-adrenergic modulation of calcium channels in frog ventricular heart cells. Nature 307:371372.

Birks RI, Cohen MW (1968) The influence of internal sodium on the behavior of motor nerve endings. Proc Roy Soc Lond Ser B 170:401421

Crawford AC (1975) Lithium ions and the release of transmitter at the frog neuromuscular junction. J Physiol 246:109-142.

D'Alonzo AJ, Grinnell $\Lambda \mathrm{D}$ (1985) Profiles of evoked release along the length of frog motor nerve terminals. J Physiol 359:235-258.

DiPolo R, Beauge L (1983) The calcium pump and sodium-calcium exchange in squid axons. Annu Rev Physiol 45:313-324.

Dodge FA, Rahamimoff R (1967) Co-operative action of calcium ions in transmitter release at the neuromuscular junction. J Physiol 193: $419-432$.

Doroshenko PA, Kostyuk PG, Martynyuk AE, Kursky MD, Vorobetz ZD (1984) Intracellular protein kinase and calcium inward currents in perfused neurones of the snail Helix pomatia. Neuroscience 11: 263-267.

Erulkar SD, Rahamimoff R (1978) The role of calcium ions in tetanic and post-tetanic increase of miniature end-plate potential frequency. J Physiol 278:501-511.

Ginsburg S, Rahamimoff R (1983) Is extracellular calcium buffering involved in regulation of transmitter release at the neuromuscular junction? Nature 306:62-64.

Grinnell AD (1985) Partial denervation of the frog sartorius causes enhanced transmitter release at surviving junctions. Soc Neurosci Abstr 11:916.

Grinnell AD (1988) Synaptic plasticity following motor nerve injury in frogs. In: The current status of peripheral nerve regeneration (Gordon T, ed), pp 223-234. New York: Liss.

Grinnell AD, Herrera AA (1980) Physiological regulation of synaptic effectiveness at frog neuromuscular junctions. J Physiol 307:301-317.

Grinnell AD, Herrera AA (1981) Specificity and plasticity of neuromuscular connections: long-term regulation of motoneuron function. Prog Neurobiol 17:203-282.

Grinnell $\Lambda D$, Pawson PA (1989) Dependence of spontaneous release at frog junctions on synaptic strength, external calcium, and terminal length. J Physiol 418:397-410.

Grinnell AD, Trussell LO (1983) Synaptic strength as a function of motor unit size in the normal frog sartorius. J Physiol 338:221-241.

Herrera AA, Grinnell AD (1980) Transmitter release from frog motor nerve terminals depends on motor unit size. Nature 287:649-651.

Herrera AA, Grinnell AD (1981) Contralateral denervation causes enhanced transmitter release from frog motor nerve terminals. Nature 291:495-497.
Herrera AA, Grinnell AD (1985) Effects of changes in motor unit size on transmitter release at the frog neuromuscular junction. J Neurosci 5:1896-1900.

Herrera AA, Scott DR (1985) Motor axon sprouting in frog sartorius muscles is not altered by contralateral axotomy. J Neurocytol 14:145156.

Herrera AA, Grinnell AD, Wolowski B (1985a) Ultrastructural correlates of naturally occurring differences in transmitter release efficacy in frog motor nerve terminals. J Neurocytol 14:193-202.

Herrera AA, Grinnell AD, Wolowski B (1985b) Ultrastructural correlates of experimentally altered transmitter release efficacy in frog motor nerve terminals. Neuroscience 16:491-500.

Katz B (1969) The release of neural transmitter substances. Liverpool: Liverpool UP.

Kuno M, Turkanis SA, Weakly JN (1971) Correlation between nerve terminal size and transmitter release at the neuromuscular junction of the frog. J Physiol 213:545-556.

Letinsky MS, DeCino PA (1980) Histological staining of pre- and postsynaptic components of amphibian neuromuscular junctions. $J$ Neurocytol 9:305-320.

Lev-Tov A, Rahamimoff R (1980) A study of tetanic and post-tetanic potentiation of miniature end-plate potentials at the frog neuromuscular junction. J Physiol 309:247-273.

Lowe DA, Richardson BP, Taylor P, Donatsch P (1976) Increasing intracellular sodium triggers calcium release from bound pools. $\mathrm{Na}$ ture 260:337-338.

Luff AR, Proske U (1976) Properties of motor units of the frog sartorius muscle. J Physiol 258:673-685.

Magleby KL, Zengel JE (1976a) Augmentation: a process that acts to increase transmitter release at the frog neuromuscular junction. $J$ Physiol 257:449-470.

Magleby KL, Zengel JE (1976b) Long term changes in augmentation, potentiation, and depression of transmitter release as a function of repeated synaptic activity at the frog neuromuscular junction. I Physiol 257:471-494.

Magleby KL, Zengel JE (1976c) Stimulation-induced factors which affect augmentation and potentiation of transmitter release at the neuromuscular junction. J Physiol 260:687-717.

Meiri H, Erulkar SD, Lerman T, Rahamimoff R (1981) The action of the sodium ionophore, monensin, on transmitter release at the frog neuromuscular junction. Brain Res 204:204-208.

Meiri H, Zelingher J, Rahamimoff R (1986) A possible involvement of the $\mathrm{Na}-\mathrm{Ca}$ exchanger in regulation of transmitter release at the frog neuromuscular junction. In: Calcium neuronal function and transmitter release (Rahamimoff R, Katz B, eds), pp 239-256. Boston: Martinus Nijhoff.

Melinek R, Lev-Tov A, Meiri H, Erulkar SD, Rahamimoff R (1982) Regulatory role of intracellular sodium ions in neurotransmitter secretion. Isr J Med Sci 18:37-43.

Miledi R, Thies R (1971) Tetanic and post-tetanic rise in frequency of miniature end-plate potentials in low-calcium solutions. J Physiol 212:245-257.

Misler S, Hurlbut WP (1983) Post-tetanic potentiation of acetylcholine release at the frog neuromuscular junction develops after stimulation in $\mathrm{Ca}^{2+}$-free solutions. Proc Natl Acad Sci USA 80:315-319.

Moskowitz N, Puszkin S (1985) A unified theory of presynaptic chemical neurotransmission. J Theor Biol 112:513-534.

Pawson PA, Grinnell AD (1984) Posttetanic potentiation in strong and weak neuromuscular junctions: physiological differences caused by a differential $\mathrm{Ca}^{2+}$-influx. Brain Res 323:311-315.

Pawson PA, Grinnell AD (1986) Physiological bases for differing synaptic efficacy in frog neuromuscular junctions. In: Calcium, neuronal function and transmitter release (Rahamimoff $\mathrm{R}, \mathrm{Katz} \mathrm{B}$, eds), pp 261-275. Boston: Martinus Nijhoff.

Pawson PA, Grinnell AD (1989) Seasonal changes in the normal variability in release properties of motor nerve terminals in Rana pipiens. Brain Res 495:182-188.

Pockett S, Slack JR (1982) Pruning of axonal trees results in increasing efficacy of surviving nerve terminals. Brain Res 243:350-353.

Propst JW, Ko C-P (1987) Correlations between active zone ultrastructure and synaptic function studied with freeze fracture of physiologically identified neuromuscular junctions. J Neurosci 7:36543664.

Rahamimoff R, Erulkar SD, Lev-Tov A, Meiri H (1978a) Intracellular 
and extracellular calcium ions in transmitter release at the neuromuscular synapse. Ann NY Acad Sci 307:583-598.

Rahamimoff R, Meiri H, Erulkar SD, Barenholz Y (1978b) Changes in transmitter release induced by ion-containing liposomes. Proc Natl Acad Sci USA 75:5214-5216.

Rahamimoff R, Lev-Tov A, Meiri H (1980) Primary and secondary regulation of quantal transmitter release: calcium and sodium. J Exp Biol 89:5-18.

Reichardt LF, Kelly RB (1983) A molecular description of nerve terminal function. Annu Rev Biochem 52:871-926.

Ridge RMAP, Thompson AM (1980) Electrical responses of muscle fibres in a small foot muscle of Xenopus laevis. J Physiol 306:41-49.

Rosenthal J (1969) Post-tetanic potentiation at the neuromuscular junction of the frog. J Physiol 203:121-133.

Smith SJ, Augustine GJ, Charlton MP (1985) Transmission at voltageclamped giant synapse of the squid: evidence for cooperativity of presynaptic calcium action. Proc Natl Acad Sci USA 82:622-625.
Sulakhe PV, St. Louis PJ (1980) Passive and active calcium fluxes across plasma membranes. Prog Biophys Mol Biol 35:135-195.

Trussell LO, Grinnell AD (1985) The regulation of synaptic strength within motor units of the frog cutaneous pectoris muscle. J Neurosci 5:243-254.

Werle MJ, Herrera AA, Grinnell AD (1984) Ultrastructural uniformity along branches of frog motor nerve terminals. Soc Neurosci Abstr 10:919.

Wilkinson L (1988) SYSTAT: The system for statistics, pp 651-704. Evanston, IL: SYSTAT

Zengel JE, Magleby KL (1981) Changes in miniature endplate potential frequency during repetitive nerve stimulation in the presence of $\mathrm{Ca}^{2+}$, $\mathrm{Ba}^{2+}$ and $\mathrm{Sr}^{2+}$ at the frog neuromuscular junction. J Gen Physiol 77: 503-529.

Zengel JE, Magleby KL (1982) Augmentation and facilitation of transmitter release. J Gen Physiol 80:583-611. 